\title{
A Multivariate Analysis of the Effect of Mobile Phone Money Transfer on Micro and Small Enterprises, Thika Town (Kenya)
}

\author{
Beatrice Karanja Kimani ${ }^{1}$, Jemimah Wangui Muraya ${ }^{1}$, Christopher Ouma Onyango ${ }^{2}$ \\ ${ }^{1}$ Department of Statistics and Computer Science, Moi University, Eldoret, Kenya \\ ${ }^{2}$ Department of Statistics and Actuarial Science, Kenyatta University, Nairobi, Kenya
}

Email address:

beatiy.kimani@gmail.com (Beatrice K. K.), jemuraya@yahoo.com (Jemimah W. M.), chrisouma2004@yahoo.co.uk (Christopher O. O.)

\section{To cite this article:}

Beatrice Karanja Kimani, Jemimah Wangui Muraya, Christopher Ouma Onyango. A Multivariate Analysis of the Effect of Mobile Phone Money Transfer on Micro and Small Enterprises, Thika Town (Kenya). American Journal of Theoretical and Applied Statistics.

Vol. 5, No. 3, 2016, pp. 108-114. doi: 10.11648/j.ajtas.20160503.15

Received: April 13, 2016; Accepted: April 20, 2016; Published: May 3, 2016

\begin{abstract}
The introduction of mobile money transfers (MMT) services has increased access to banking services among business entrepreneurs. This facilitates quick and secure platform for small savings to a majority of both rural and urban populations. The MSEs are increasingly adopting the use of mobile money transfers to increase the quality of their services and promote growth. However, limited research has been done on the impact of MMT services on the small and micro-enterprises. This study aimed at investigating the effect of mobile money transfers on the MSEs success factors, growth and expansion. The survey was conducted through administration of questionnaires and interviews of MSEs operators in Thika Town, Kenya. Data analysis was done using multivariate techniques, to a deeper extent the factor analysis. It was evident from the factor analysis, using principal component analysis that three factors were extracted which loaded highly on given variables. The factors were suggested to be demographic, accessibility and satisfaction, after considering the variables that loaded on each factor. The findings were expected to be useful to the mobile payments technology providers, by offering greater entrepreneur support to the micro business operators and enhance customers' convenience to use the technology. The government can also use these findings when designing appropriate plan of action to encourage many more business operators to adopt the MMT services through funding and other platforms.
\end{abstract}

Keywords: Mobile Money Transfer, Micro and Small Enterprises, Factor Analysis, Principal Component, Factor Loadings

\section{Introduction}

Background of Study: In Kenya, the micro and small enterprises are multifariously referred. They largely fall under the popular informal sector called 'Jua Kali' which is a swahili term meaning entrepreneurs. They are business people who invest in informal businesses as a way of sustainability. It is estimated that this informal sector in the country absorbs 50 percent of new non-farm employment seekers, and has employment growth of 12 to 14 percent. Thus this sector is seen to contribute about 30 percent of total employment and 3 percent of GDP. [8]. The number of enterprises in Kenya had grown from 910,000 in 1993 to 1.8 million in 2006 [1]. This informal sector constitutes $98 \%$ of all businesses in the country. According to Baseline survey $2006,64.3 \%$ of the MSEs were in trade, $14.8 \%$ in services, $13.4 \%$ in manufacturing while $7.7 \%$ involved in other activities. The development of competitive and resilient MSEs forms an integral component of Kenya's initiatives to be globally competitive and prosperous nation with a high quality of life by 2030 [5] Although huge amounts of money have been spent on MSEs through projects and programs in recent years, their impact on survival and development of the enterprises has been low, as their mortality rate remained high [4]." Only about $10.4 \%$ of MSEs, receive credit and other financial services from the formal banking sector, who regard the informal sector as risky and not commercially viable" [11]. Many of these micro business operators do not have bank accounts while those who do, find the bank accounts cumbersome to 
operate as they have to leave their businesses unattended in order to conduct transactions in a bank. In fact many developing countries, "9 out of 10 people do not have a bank account or access to basic financial services" [14]. The adoption of mobile telephony has been on the rise in the recent years in Kenya. According to statistics provided by the Central Bank of Kenya, there were 825 million mobile transactions up to November 2014, compared to 732 million transactions in 2013 [9]. This increased accessibility to mobile phones have introduced changes in most sectors of the economy and particularly the urban informal sector consequently Jua Kali Business (MSEs) changing their business and operation environment, thereby creating an impact on Kenya's fastest growing sector and employer [7]. The related mobile technological innovations have dramatically enhanced the capabilities of the mobile phones. [16]. There are several innovations in mobile telephony that are assisting MSEs in the informal sector. For example, the introduction of mobile phone money transfers is transforming the informal sector in Kenya. Since March 2007, when Safaricom mobile operator launched the mobile money transfer (MMT), mobile payment system has become popular with both the banked and the unbanked population. Micro-business operators in Kenya have adopted the use of the mobile payments as a way of transacting their business because of the relative affordability of mobile phones and the mobile banking services they offer. "Various transactions are carried out using mobile payments such as paying suppliers for goods and services, paying bills, sending money to friends and relatives, withdrawing cash and topping up airtime accounts" [10]. It is therefore worth noting that Proprietors and small businesses in Kenya benefited hugely from the mobile phone revolution in the introduction of MMT services as they are able to make savings and gain access to more customers and new services.

\section{Literature Review}

A 'micro enterprise' is defined as having 10 or fewer workers, 'small enterprises' have from 11 to 50 employees and medium enterprises have from 51 to 100 workers [4]. Farm holdings are excluded in the MSEs definitions except farm based enterprises that involve some sort of processing before marketing. Thus Micro and small enterprises cover a range of informal economic activities with one to fifty employees. Censuses indicate that micro enterprises comprise of the lion share of enterprises in Kenya while there are a few medium one [13]. Regarding the scope, it was reported that close to $70 \%$ of MSEs are in the trade sector. This means a large proportion of MSEs are involved in buying and selling goods and commodities to generate income. [3]. Recently," according to the economic survey 2003 this sector grew from 4.2 million people in 2000 to 5.1 million persons in 2002, accounting for 74.2 of the total persons engaged in employment. The sector contributed up to $18.4 \%$ of the country's gross domestic product". [5].
The micro businesses are spread throughout the country with huge clusters in the market areas and near shopping centers. This enables them to easily access the M-Pesa service providers for registration and to make cash deposits into their accounts. The mobile payment providers' are well distributed and easily accessible to the micro business owners for support of their services [10].

In recent times one of the mobile phone service providers in Kenya, Safaricom, launched a new service dubbed 'Lipa na M-pesa' to enable consumers pay for goods and services worth between Sh.10 to Sh. 70,000, from small scale traders and businesses without a transaction fee [12].

As a result of flexibility and low production, the micro and small enterprises are important in raising economic efficiency of a country. The performance of MSEs must therefore be increased to effectively respond to challenges of creating productivity and sustainable employment opportunities. Sustainable job creation income in turn reduces poverty [3].

In recent years the MSE sector has consistently registered higher growth rate compared to the overall industrial sector. The major advantage of this sector is its employment potential at low capital costs. Available statistics indicate that the sector employs an estimated 31 million persons spread over 12.8 million enterprises and the labor intensity is estimated to be almost 4 times higher than the large enterprises. This dramatic increase is largely due to retrenchment in both public and private sector. [3]

\section{Methodology}

\subsection{Introduction}

The study adopted a descriptive survey that sought to examine the contribution of MMT services to the success and growth of MSEs. Descriptive design was used because the research involved collection of information by interviewing and administering a questionnaire to a sample of individuals. The design enabled the researcher to define the dependent and independent variables studied.

\subsection{Sampling Design and Technique}

The population of interest, obtained from the chamber of commerce and industry, Thika town had an estimated 12,000 micro and small enterprises and more specifically 5000 traders in the CBD. The study employed a crosssectional survey. The study targeted population based on case study of what happens in MSEs in Thika town. This would hence reflect on undertakings of other MSEs in the country. The sampling units were business units like shops, sheds and workshops. The researcher used quota sampling method. The reason for using this method was because the study aimed at capturing information from all the diverse groups in the informal sector, of different age groups, different business ventures, income, gender and level of education. The quotas were divided into three categories as follows. 
$\begin{array}{ll}\text { Categories } & \text { Licensed traders operating in: } \\ 1 & \text { Permanent buildings }\end{array}$

2

3
Semi-permanent or temporary structures

Jua kali sheds or Open air places
Salons, barber shops, cyber cafes, Stationers photocopying \& printing premises, Mobile phone dealers and Repairers, beauty and cosmetic shops.

(Approximately 3500)

Includes dealers in second hand clothes, shoes and book sellers around the main bus stage, (Approximately 1000)

Artisans who include Sign writers, key cutters, cobblers shoe shiners and mechanics. (Approximately 500)

The coefficients $a_{11}, a_{12} \ldots$ aim are weights in the same way as regression coefficients. For example, the coefficient $a_{l l}$ shows the effect on variable $Y_{l}$ of a one-unit increase in $F_{l}$. The coefficients are called loadings [17].

Given the equations (1) above, which show the variables $Y_{1} \ldots Y_{i}$ in terms of the factors $F_{1} \ldots F_{m}$, it is possible to solve the equations for the factor scores, so as to obtain a score on each factor for each subject. In other words, equations of the form

$$
\begin{gathered}
F_{1}=b_{11} Y_{1}+b_{12} Y_{2} \ldots b_{1 n} Y_{i} \\
F_{2}=b_{21} Y_{1}+b_{22} Y_{2} \ldots b_{2 n} Y_{i} \\
\ldots \\
F_{m}=b_{m 1} Y_{1}+b_{m 2} Y_{2} \ldots b_{m n} Y_{i}
\end{gathered}
$$

However, problems are caused by the unique factors, because when they are included with the common factors, there are more factors than variables, and no exact solution for the factors is available. Thus the preference a variety of factor analysis called principal component analysis (PCA).The PCA model doesn't contain unique factors: all the variance of the observed variables is assumed to be attributable to the common factors, so that the communality for each variable is one. As a consequence, an exact solution for the factors is available in PCA, as in equations (2) above [18].

\section{Results and Discussion}

\subsection{Analyzing the Demographic Characteristics}

Ninety four responses were completed by the participating micro-business operators, but only ninety were usable for analysis. Table 1 clearly indicates there were more female respondents (48\%, 42\%). Majority of the respondents (57\%), were middle aged, that is between 25-44 years. Over half of the operators had college or university education, while about $47 \%$ had been in business less than five years. It was worth noting that over $65 \%$ of the respondents had been using MMT services for over three years, probably since the launch of the first Mobile phone service provider launched its mobile money transfer services where the $a_{i} s$ are the factor loadings (or scores) for variable $i$ and $\mathrm{e}_{\mathrm{i}}$ is the part of variable $Y_{\mathrm{i}}$ that cannot be 'explained' by the factors

Factor analysis seeks to find the coefficients $a_{11}, a_{12} \ldots a_{i m}$ which best reproduce the observed variables from the factors. 
Table 1. Anova Improved business performance.

\begin{tabular}{|c|c|c|c|c|c|c|}
\hline & & Sum of Squares & df & Mean Square & $\mathbf{F}$ & Sig. \\
\hline \multirow{3}{*}{ Age } & Between Groups & .356 & 4 & .089 & 4.722 & .002 \\
\hline & Within Groups & 1.600 & 85 & \multirow{2}{*}{.019} & & \\
\hline & Total & 1.956 & 89 & & & \\
\hline \multirow{3}{*}{ Gender } & Between Groups & 0.039 & 1 & .039 & \multirow{3}{*}{1.786} & \multirow{3}{*}{.18} \\
\hline & Within Groups & 1.917 & 88 & .022 & & \\
\hline & Total & 1.956 & 89 & & & \\
\hline \multirow{3}{*}{ Educ Level } & Between Groups & 0.305 & 2 & 0.153 & \multirow{3}{*}{8.047} & \multirow{3}{*}{.001} \\
\hline & Within Groups & 1.65 & 87 & 0.019 & & \\
\hline & Total & 1.955 & 89 & & & \\
\hline
\end{tabular}

Table 2. Anova Improved business performance.

\begin{tabular}{|c|c|c|c|c|c|c|}
\hline & & Sum of Squares & df & Mean Square & $\mathbf{F}$ & Sig. \\
\hline \multirow{3}{*}{ Years of operation } & Between Groups & .066 & 4 & .016 & \multirow[t]{3}{*}{.740} & \multirow[t]{3}{*}{0.567} \\
\hline & Within Groups & 1.890 & 85 & .022 & & \\
\hline & Total & 1.956 & 89 & & & \\
\hline \multirow[t]{3}{*}{ Years of MMT use } & Between Groups & 0.173 & 3 & .058 & \multirow[t]{3}{*}{2.773} & \multirow[t]{3}{*}{0.046} \\
\hline & Within Groups & 1.783 & 86 & 021 & & \\
\hline & Total & 1.956 & 89 & .021 & & \\
\hline \multirow{3}{*}{ Business type } & Between Groups & 0.137 & 3 & .046 & \multirow{3}{*}{2.166} & \multirow{3}{*}{0.098} \\
\hline & Within Groups & 1.818 & 86 & .021 & & \\
\hline & Total & 1.956 & 89 & & & \\
\hline
\end{tabular}

\subsection{ANOVA Tests on Demographic Characteristics}

\subsubsection{Tests Between Age, Education Level, Gender and Improved Business on Using MMT}

The ANOVA test was performed and determined that the age, education level and improved business performance after adopting MMT services were highly significant since the P-values were less than 0.05 .

As for gender and improved performance the P-value was $0.185>0.05$, hence gender does not influence the improvement of businesses after MMT adoption.

\subsubsection{Tests Between Years of Operation, Years of Using MMT and Improved Performance}

- The years of operation of the business were insignificant in regard to business performance as the Pvalue $0.567>0.05$, the period of usage of the MMT service was only slightly significant with a $\mathrm{P}$-value of 0.046 .

The type of business operated was also insignificant with regard to improved business performance, $\mathrm{P}$-value of $0.098>$ 0.05 .

\subsection{ANCOVA Tests on Years of using MMT Services and Improved Business Performance, with Business Type and Years of Operation as Covariates}

Tests of Between-Subjects Effects
Table 3(a). Dependent Variable: Improved business performance.

\begin{tabular}{llllll}
\hline Source & $\begin{array}{l}\text { Type III Sum } \\
\text { of Squares }\end{array}$ & df & $\begin{array}{l}\text { Mean } \\
\text { Square }\end{array}$ & F & Sig. \\
\hline Corrected Model & $.284^{\mathrm{a}}$ & 5 & .057 & 2.852 & .020 \\
Intercept & 7.856 & 1 & 7.856 & 394.710 & .000 \\
BusTyp & .073 & 1 & .073 & 3.663 & .059 \\
YrOOpr & .016 & 1 & .016 & .817 & .369 \\
YrsMMT & .209 & 3 & .070 & 3.500 & .019 \\
Error & 1.672 & 84 & .020 & & \\
Total & 96.000 & 90 & & & \\
Corrected Total & 1.956 & 89 & & & \\
\hline
\end{tabular}

a $\mathrm{R}$ Squared $=.145$ (Adjusted R Squared $=.094$ )

From the table above it was evident that the overall model became very significant at 0.02 , with the type of business and year of business operation used as covariates. In fact, the years of usage of MMT services had a P-value of $0.019<$ 0.05 , thus there was significant effect on years of MMT usage on Improved business performance after adoption of MMT after controlling the effect of business type and years of business operation.

Years of MMT usage explained $14.5 \%$ of the variance in improved business performance.

\subsection{Tests on Years of Using MMT Services and Improved Business Performance with Age, Gender and Education Level as Covariates}

Tests of Between-Subjects Effects 
Table 3(b). Dependent Variable: Improved business performance.

\begin{tabular}{llllll}
\hline Source & $\begin{array}{l}\text { Type III Sum of } \\
\text { Squares }\end{array}$ & df & $\begin{array}{l}\text { Mean } \\
\text { Square }\end{array}$ & F & Sig. \\
\hline Corrected Model & .430 & 6 & .072 & 3.901 & .002 \\
Intercept & 1.578 & 1 & 1.578 & 85.886 & .000 \\
Gender & .050 & 1 & .050 & 2.739 & .102 \\
Educlv & .042 & 1 & .042 & 2.307 & .133 \\
Age & .174 & 1 & .174 & 9.453 & .003 \\
YrsMMT & .200 & 3 & .067 & 3.632 & .016 \\
Error & 1.525 & 83 & .018 & & \\
Total & 96.000 & 90 & & & \\
Corrected Total & 1.956 & 89 & & & \\
\hline
\end{tabular}

a R Squared =.220 (Adjusted R Squared $=.164$ )

Table 3(b) also showed clearly that the overall model once again became very significant at 0.002 , with education level, age and gender used as covariates. The years of MMT usage was therefore significant on improved business performance at P-value $0.016<0.05$ after controlling the social demographic factors.

\subsection{ANOVA Tests on Accessibility, Costs, Convenience and Satisfaction}

The analysis of variance shown in table 5 above indicated that easy accessibility to MMT services greatly influenced the improvement of business performance at a $\mathrm{P}$-value $0.00<$ 0.05 .

The MSEs operators were completely satisfied with the MMT services, whereby satisfaction implied recommendation to others due to greatly being significant in business expansion and improvement due to adoption of the mobile money transfers P-value $0.00<0.05$.

Table 4(a). Improved business performance.

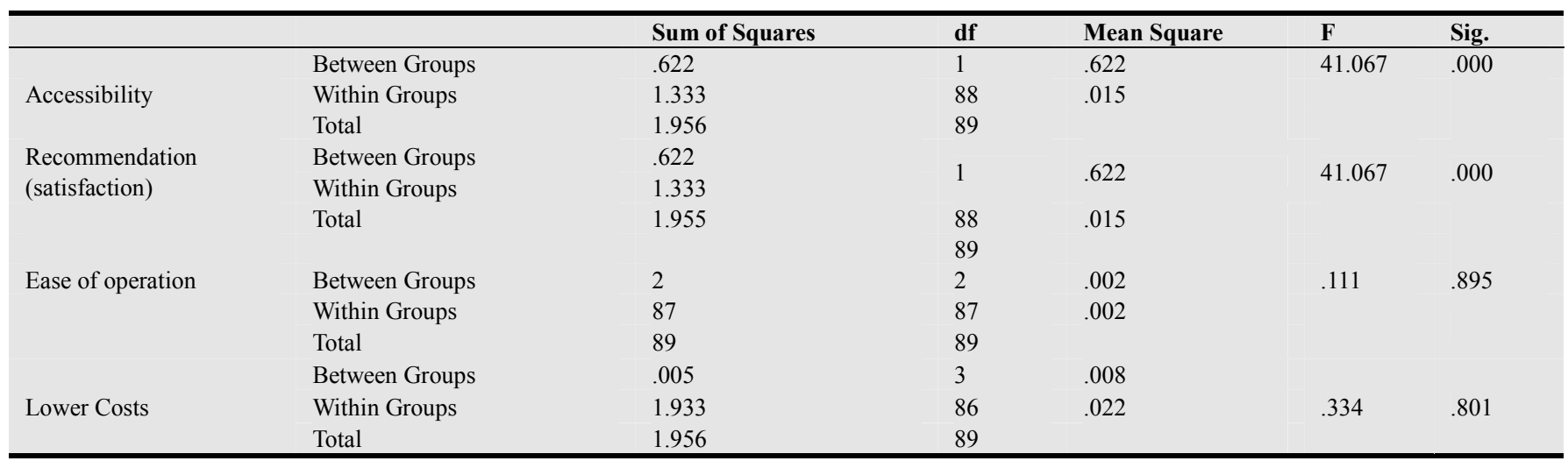

On the other hand ease of operation and lower costs of doing business with MMTs had no significance influence on business performance. The P-value were far greater than 0.05 .

\subsection{Further ANCOVA Tests on Ease of Operation and Efficiency}

Tests of Between-Subjects Effects

Table 4(b). Dependent Variable: Improved business performance.

\begin{tabular}{llllll}
\hline Source & $\begin{array}{l}\text { Type III Sum of } \\
\text { Squares }\end{array}$ & df & $\begin{array}{l}\text { Mean } \\
\text { Square }\end{array}$ & F & Sig. \\
\hline Corrected Model & $.515^{\text {a }}$ & 3 & .172 & 10.257 & .000 \\
Intercept & 1.693 & 1 & 1.693 & 101.079 & .000 \\
Accessible & .510 & 1 & .510 & 30.473 & .000 \\
Operation & .253 & 2 & .126 & 7.543 & .001 \\
Error & 1.440 & 86 & .017 & & \\
Total & 96.000 & 90 & & & \\
Corrected Total & 1.956 & 89 & & & \\
\hline
\end{tabular}

a R Squared $=.264$ (Adjusted R Squared $=.238$ )

The analysis of covariance was further carried out with the accessibility factor being a covariate. The results as shown in table 6 interestingly gave the corrected model to be significant at $\mathrm{P}$-value $0.00<0.05$, hence there was a significant effect of ease of MMT operation on business performance $(\mathrm{P}$-value $0.001<0.05)$ after controlling ease of access to the MMT services. The ease to operate and efficiency thus explained $26.4 \%$ of the variance in business improvement.

\subsection{Factor Analysis}

Factor analysis was further used to find factors (components) among the observed variables. The aim was to group variables with similar characteristic. Principal component analysis was used to sort out the significant factors among variables determined by eigen value of greater than one and a varimax rotation suppressing absolute values of less than 0.50 .

\subsubsection{Interpretation of Output}

Table 5. Descriptive statistics.

\begin{tabular}{llll}
\hline & Mean & Std. Deviation & Analysis N \\
\hline Age & 2.33 & 1.049 & 90 \\
Education level & 3.64 & .547 & 90 \\
Years of operation & 2.57 & 1.152 & 90 \\
Years of using MMT service & 3.44 & .888 & 90 \\
Recommendation to Others & 1.07 & .251 & 90 \\
MMT easily Accessible & 1.46 & .639 & 90 \\
MMT lower costs of doing & 2.16 & 1.016 & 90 \\
business & & & \\
MMT ease of operation \& & 1.42 & .560 & 90 \\
efficient & 1.02 & .148 & 90 \\
Improved business performance & & & \\
\hline
\end{tabular}


Table 6. Communalities

\begin{tabular}{lll}
\hline & Initial & Extraction \\
\hline Age & 1.000 & .714 \\
Education level & 1.000 & .310 \\
Years of operation & 1.000 & .666 \\
Years of using MMT service & 1.000 & .731 \\
Recommendation to Others & 1.000 & .660 \\
MMT easily Accessible & 1.000 & .846 \\
MMT lower costs of doing business & 1.000 & .389 \\
MMT ease of operation \& efficient & 1.000 & .783 \\
Improved business performance & 1.000 & .746 \\
\hline
\end{tabular}

The first output from the factor analysis was the descriptive statistics for all the 9 variables entered as shown in table 5. Typically the mean suggested that the education level and years of using MMT influenced the adoption of MMT services by MSE operators, due to their higher means of 3.64 and 3.44 respectively.

The table 6 of communalities showed how much of the variance in the variable had been accounted for by the extracted factors. The initial communalities under PCA work on assumption that all variance is common; hence before extraction it is equal to one. Hence after extraction the values show the proportion of each variable's variance that can be explained by the retained factors. Thus, for instance $84.6 \%$ of the variance in MMT ease of accessibility was accounted for, while $78.3 \%$ of variance in MMT ease of operation and efficiency was accounted for.

\subsubsection{Extraction Method, Principal Component Analysis and Varimax Rotation}

Table 7. Total variance explained.

\begin{tabular}{|c|c|c|c|c|c|c|c|c|c|}
\hline \multirow[t]{2}{*}{ Component } & \multicolumn{3}{|c|}{ Initial Eigenvalues } & \multicolumn{3}{|c|}{ Extraction Sums of Squared Loadings } & \multicolumn{3}{|c|}{ Rotation Sums of Squared Loadings } \\
\hline & Total & $\%$ of Variance & Cumulative \% & Total & $\%$ of Variance & Cumulative \% & Total & $\%$ of Variance & Cumulative \% \\
\hline 1 & 2.357 & 26.189 & 26.189 & 2.357 & 26.189 & 26.189 & 2.039 & 22.650 & 22.650 \\
\hline 2 & 1.954 & 21.712 & 47.901 & 1.954 & 21.712 & 47.901 & 1.937 & 21.527 & 44.177 \\
\hline 3 & 1.534 & 17.044 & 64.945 & 1.534 & 17.044 & 64.945 & 1.869 & 20.768 & 64.945 \\
\hline 4 & .986 & 10.960 & 75.906 & & & & & & \\
\hline 5 & .734 & 8.159 & 84.065 & & & & & & \\
\hline 6 & .450 & 4.996 & 89.061 & & & & & & \\
\hline 8 & .373 & 4.141 & 97.737 & & & & & & \\
\hline 9 & .204 & 2.263 & 100.000 & & & & & & \\
\hline
\end{tabular}

Extraction Method: Principal Component Analysis.

Table 7 showed all factors extractable from the analysis along with their Eigen values, the percentage of variance attributable to each factor and their cumulative variances. It is worth noting that the first factor accounted for $26.189 \%$ of the variance, the second $21.712 \%$ and the third $17.044 \%$. All the remaining factors were not significant.

Table 8. Rotated component (Factor) matrix.

\begin{tabular}{llll}
\hline & \multicolumn{3}{l}{ Component } \\
\cline { 2 - 4 } & $\mathbf{1}$ & $\mathbf{2}$ & $\mathbf{3}$ \\
\hline Years of operation & .808 & & \\
Age & .802 & & \\
Years of using MMT service & .798 & & \\
Improved business performance & & .853 & \\
Recommendation to Others & & .810 & \\
Education level & & & .859 \\
MMT ease of operation \& efficient & & & .814 \\
MMT easily Accessible & & & .565 \\
MMT lower costs of doing business & & & \\
\hline
\end{tabular}

Extraction Method: Principal Component Analysis.

Rotation Method: Varimax

Rotation of the component matrix reduced the number of factors on which the variables had high loadings. From the table above, it was clear that years of operation, age and years of using MMT service loaded on Factor 1, while improved performance after using MMT and recommendation to others, loaded on Factor 2. The remaining variables, MMT ease operation, Accessibility and Lower costs substantially loaded on Factor 3.

\section{Conclusion and Recommendations}

From the findings and subsequent analysis, the conclusions were as follows;

There was a statistical significant relationship between age, education level and improved business performance after adopting MMT services. This was determined by the Pvalues of 0.002 and 0.001 respectively being less than 0.05.There was no significant relationship between Gender and adoption of MMT services (P-value 0.185)

Table $2, p=0.567$, revealed that there was no significant relationship between years of business operation and business success after MMT use. From the same table a Pvalue $=0.046$, revealed a very slight significant relationship between Years of MMT usage and business improvement.

Further analysis on this finding was done to confirm the significance by execution of ANCOVA. By controlling the effects of business type and years of operation (as covariates), there was a indeed a significant relationship between Years of MMT use and improved business performance, $\mathrm{P}$-value $=0.019$.

There was no significant relationship between lower costs of operation, ease of operation and improved performance recorded in the same table $5, \mathrm{P}=0.801$ and $\mathrm{P}=0.895$ respectively.

It was however not clear why the ease in operation and efficiency was not significant, hence further analysis of ANCOVA was done, controlling accessibility as a covariate, 
the model became significant and a P-value $=0.001$, hence table 6 revealed a significant relationship between ease and efficiency of operating MMT services and improved business performance, controlling effects of accessibility. This meant that the ease of operating MMT services from anywhere anytime did influence business performance without necessarily being near a service provider (accessibility).

Factor analysis, revealed that 3 factors (components) were identified from all the 9 variables originally used in the analysis. The factors were extracted by use of principal component analysis determined by criteria of Eigen vector greater than one. Out of the 3 Factors, the first accounted for $26.189 \%$ of the variance, the second $21.712 \%$ and the third $17.044 \%$.

Table 8 recorded of output of the rotated factor loadings which represented the correlations between the variables and the factors of possible range -1 to 1 , although the output was made easier to read by suppressing correlations below 0.5 for meaningful interpretations

Hence the Factor 1 loaded highly on years of operation, years of MMT use and Age, this factor might be called 'demographic'.

Factor 2 loaded highly on improved performance after using MMT and recommendation, this factor might be called 'satisfaction'.

Factor 3 loaded on MMT ease operation, Accessibility and Lower costs, this factor might be called 'convenience'.

In this study, analysis of variance and factor analysis was used to investigate the effects of mobile money transfers on micro and small enterprises. A similar study could be done by use of profile analysis or multiple regression to improve on findings. The study did not venture on the actual income generated from the MSEs and their relation to usage of the mobile money transfers; hence more research can be done on this. The study only concentrated on mobile money transfers, areas like mobile banking like Mshwari, and most recently Lipa na Mpesa, remain unexplored by this study. Finally this study did not differentiate the various activities and business types under the Micro and Small enterprises, hence providing an avenue for further research.

\section{References}

[1] Central Bureau of Statistics (2005) Economic review report. Government printer, Nairobi.

[2] Cornish. R. (2007) Statistics: 3.3 Factor Analysis $<$ http://www.statstutor.ac.uk/resources/uploaded/factoranalysi s.pdf $>$

[3] Government of Kenya, (1999) National Medium and Small
Enterprises Baseline Survey, Kenya. National Bureau of Statistics. <http://www.knbs.go.ke.>

[4] Government of Kenya. (2005) Session paper No.2 of 2005 on," Development of Micro and Small enterprises for wealth and employment creation for poverty reduction." Government printer. Nairobi.

[5] Government of Kenya, (2008). Kenya National Bureau of Statistics $<$ http://www.knbs.go.ke.>

[6] Hair, J. F., Anderson, R. E., Black, W. C., Tatham, R. L. (1998), Multivariate data analysis, 5th Edition, Prentice Hall, Engelwood Cliffs, New Jersey, U.S.A.

[7] International Telecommunication Union (2007), ICT free statistics home page. $<\mathrm{http} / /$ www.itu.int/itu-d/ict/statistics $>$

[8] Kenya Economic Report (2009). "Building a Globally Competitive Economy". The Kenya Institute for Public Policy Research and Analysis (KIPPRA), Nairobi, Kenya

[9] Macharia. K. (2015) "Mobile-money-transactions-hit-sh2-trillionin-2014" <<http:/www.capitalfm.co.ke/business/2015/01/>>

[10] Mbogo, M. (2010).The impact of mobile payments on success and growth of micro-business: The case of M-pesa in Kenya. Journal of language, technology \& entrepreneurship in Africa. 2(1), 180-203.

[11] Mwaura, L. M. (2011). "Factors that influence the financing of micro and small (MSEs) by commercial banks in Kenya". (Unpublished MBA Thesis, Kenyatta University) enterprises.

[12] Nation correspondent (2013, June 25).” Safaricom launches Lipan a M-pesa campaign”. Daily Nation. Business News pp 32.

[13] Parker, J. C. and Torres, T. R. (1994). "Micro-and Small-Scale Enterprise in Kenya." Results of the 1993 national Baseline Survey. GEMINI Technical Report No. 75. Development Alternatives, Inc.

[14] Pickens, M. and Brian, R. (2007). Mobile Wallets and Virtual Currencies in Financial Services, ICT Update (36). < http://ictupdate.cta.int/en/Feature-Articles/Mobile-walletsand-virtual-currencies.>

[15] Rao, C. R. (2003) Sample surveys Design, Methods and application: Handbook for Statistics 2A.

[16] Salzaman, M., Palen. L., Harper, R. (2001). Mobile Communication: Understanding Users, Adoption and Design. (Lecture) Paper presented in CHI workshop.

[17] Taylor. A. (2002) A Brief Introduction to Factor Analysis $<$ http://www.psy.mq.edu.au/psystat/other/FactorAnalysis.PDF>

[18] Widaman, K. F. (1993). Common factor analysis versus principal component analysis: Differential bias in representing model parameters? Multivariate Behavioral Research, 28, 263-311. 